\title{
Intracameral Chemotherapy (Melphalan) for Aqueous Seeding in Retinoblastoma: Bicameral Injection Technique and Related Toxicity in a Pilot Case Study
}

\author{
Francis L. Munier ${ }^{\mathrm{a}} \quad$ Marie-Claire Gaillard ${ }^{\mathrm{a}}$ Sarah Decembrini ${ }^{\mathrm{a}}$ \\ Massimo Bongiovanni ${ }^{b}$ Maja Beck-Popovic ${ }^{c}$ \\ a Jules-Gonin Eye Hospital, University of Lausanne, ${ }^{\mathrm{b}}$ Institute of Pathology, University of Lausanne, and ${ }^{\mathrm{C}}$ Unit of \\ Pediatric Hematology-Oncology, Centre Hospitalier Universitaire Vaudois, Lausanne, Switzerland
}

\section{Keywords \\ Anterior chamber fluid · Chemotherapy · Intravitreal injection - Pathology of the anterior segment . \\ Retinoblastoma $\cdot$ Aqueous seeding $\cdot$ Intracameral chemotherapy · Melphalan}

\section{Abstract}

Background: The anterior chamber has been shown by pharmacokinetic studies to represent a sanctuary never achieving a tumoricidal dose with the present administration routes, such as systemic, intra-arterial, or intravitreal injections. Method: A novel intracameral chemotherapy technique is described to control aqueous seeding in a pilot unilateral group $\mathrm{E}$ retinoblastoma case with primary aqueous seeding. Anterior segment toxicity was carefully monitored. Results: Control of the retinal tumor and vitreous seeding was achieved by intra-arterial and intravitreal chemotherapies. Sterilization of the aqueous was achieved after a first cycle of 7 melphalan injections in the anterior chamber, but relapse was noted 3.5 months later. This relapse was finally controlled with a second cycle of 6 intracameral injections targeting the posterior chamber. Corneal endothelial cell density remained stable over the injection period. Heterochromia and a progressive cataract developed, which re-

\section{KARGER}

E-Mail karger@karger.com www.karger.com/oop

\section{The Author(s) \\ Published by S. Karger AG, Basel \\ Karger \\ Open access}

This article is licensed under the Creative Commons Attribution NonCommercial-NoDerivatives 4.0 International License (CC BYNC-ND) (http://www.karger.com/Services/OpenAccessLicense) Usage and distribution for commercial purposes as well as any distribution of modified material requires written permission. quired cataract surgery. At 5 years' follow-up, the patient is tumor free with normal vision (20/20 in both eyes), full binocularity, and no metastasis. Conclusions: The present bicameral injection technique appears to be safe and effective with limited toxicity. Melphalan-induced side effects were noted on the iris and lens but with no impact on the final visual function.

(C) 2016 The Author(s)

Published by S. Karger AG, Basel

\section{Introduction}

Seeding in retinoblastoma has always been recognized as a poor prognostic factor, but it has only recently been classified into 3 classes of seeds [1]. The advent of novel routes of antimitotic drug administration, such as ophthalmic artery [2] and vitreous injections [3], completely reversed the negative prognostic value of subretinal and vitreous seeds, respectively. However, all attempts to control aqueous seeding remained unsuccessful until very recently [4], when brachytherapy was successfully used for

Presented in part in New York on September 18, 2014, during the symposium "Celebrating 100 Years of Our Retinoblastoma Center in New York" and at ARVO in Denver on May 4, 2015. 
Fig. 1. a Biomicroscopy and gonioscopy at presentation: pseudohypopyon (white triangle); iris nodules at 6 and 9 o'clock and nodules in the angle over $270^{\circ}$ (white arrows). b Ultrasonic biomicroscopy ( 35 $\mathrm{mHz}$ ) at presentation: circular invasion of the posterior chamber, including the canals of Petit and Hannover, but no involvement of the ciliary body, iris, or Schlemm's canal.
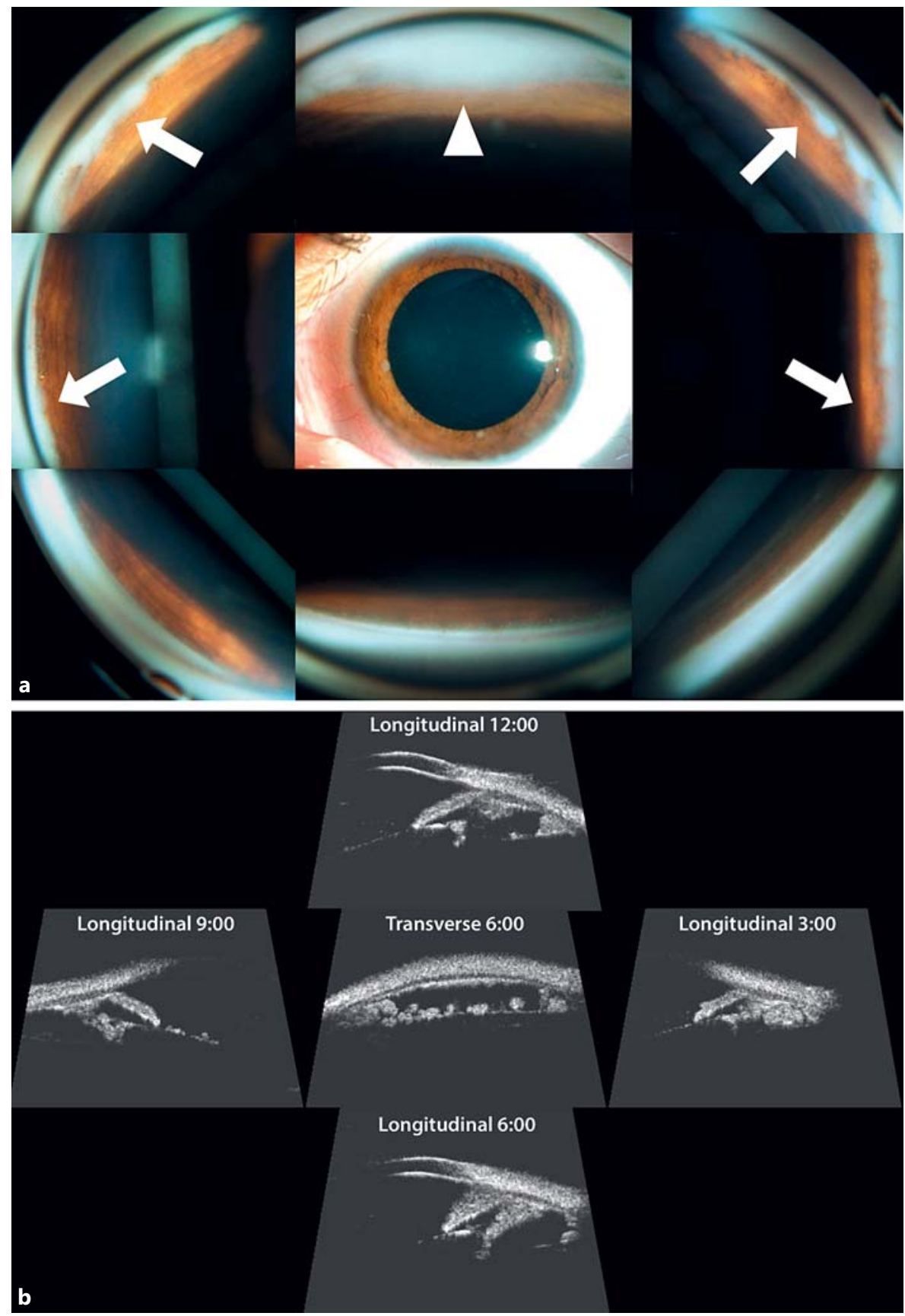

diffuse anterior retinoblastoma not involving the retina. Aqueous seeding is still considered to be one of the absolute criteria for enucleation (group E in the International Intraocular Retinoblastoma Classification) and is present in $1 \%$ of cases at presentation on biomicroscopy [5] and in $30 \%$ of cases on histopathology in primarily enucleated group E eyes [6]. This frequency rises to 65\% [7] and even
$100 \%$ [8] in cases of diffuse infiltrative and anterior diffuse variants of retinoblastoma, respectively. The occurrence of secondary aqueous seeding in the course of conservative treatment also results in a $100 \%$ enucleation rate. Here, we present a novel technique of in situ chemotherapy specifically developed to safely eradicate aqueous seeding. 

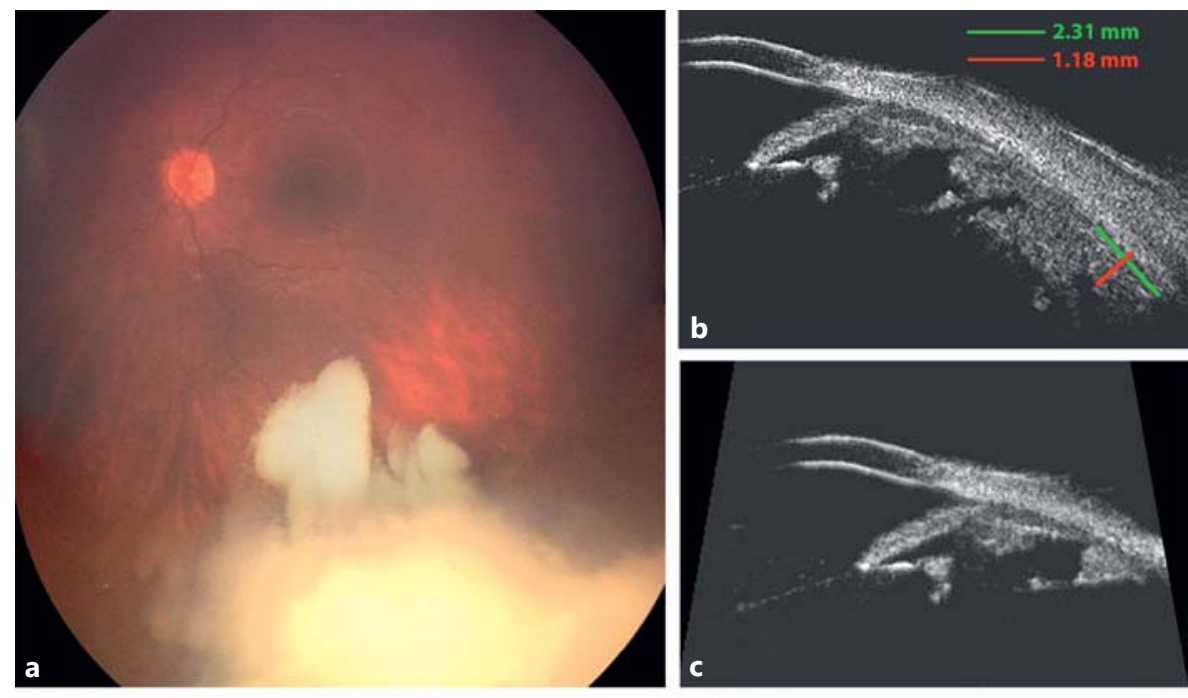

Fig. 2. a Fundus montage at presentation: inferiorly located vitreous seeding type III (cloud) masking the primary peripheral tumor. b, c Ultrasonic biomicroscopy (35 $\mathrm{mHz}$ ) of the primary peripheral tumor under the vitreous base (b) and tumor invasion of the posterior chamber (c) at presentation. d Fundus montage at full remission. e Ultrasonic biomicroscopy at complete remission: tumor-free posterior chamber. $\mathbf{f}, \mathbf{g}$ Gonioscopy at first remission (f) and at relapse $(\mathbf{g})$.
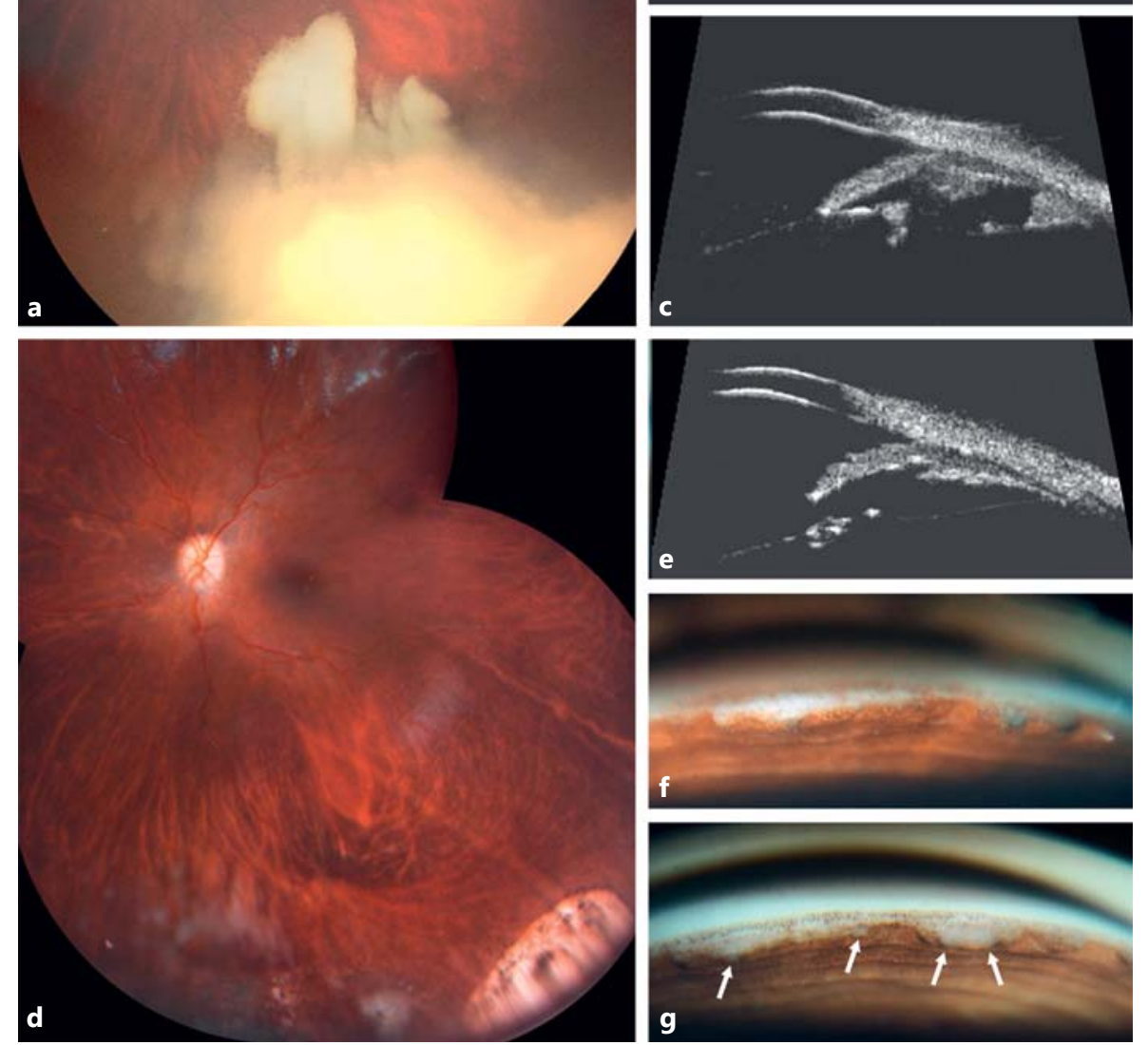

\section{Case Presentation}

This study was approved by the Swiss Federal Department of Health (authorization No. 035.0003-48) and is in accordance with the declaration of Helsinki. An 11-year-old girl presented with unilateral group $\mathrm{E}$ anterior diffuse retinoblastoma in the left eye and normal vision in both eyes with full binocularity. Biomicroscopic examination showed cells floating in the anterior chamber (AC) as well as a pseudohypopyon and 2 iris nodules at 6 and 9 o'clock (Fig. 1a). Gonioscopy revealed numerous nodules growing in the angle over $270^{\circ}$ (Fig. 1a). Ultrasonic biomicroscopy (UBM) at $35 \mathrm{mHz}$ documented a circular invasion of the posterior chamber, including the canals of Petit and Hannover, but no involvement of the ciliary body, iris, or Schlemm's canal (Fig. 1b). Anterior segment fluorescein angiography showed infraclinical (not visible on biomicroscopy) rubeosis iridis of the collarette (data not shown). The intraocular pressure

was $30 \mathrm{~mm} \mathrm{Hg}$ in the left eye (18 $\mathrm{mm} \mathrm{Hg}$ in the right eye) under tri-therapy. Fundus examination displayed massive inferiorly located vitreous seeding type III (cloud) masking the primary peripheral tumor (Fig. $2 \mathrm{a}$ ), which measured $2.3 \times 2.3 \times 1.2 \mathrm{~mm}$ at 5:30 by UBM under the vitreous base (Fig. 2b). There was no retinal detachment, and both macula and optic nerve head were tumor free.

A conservative therapeutic strategy was designed to control retinal, vitreous, and cameral disease consisting of melphalan injections as follows: intra-arterial $(2 \times$ with a total dose of $10 \mathrm{mg}$ ) followed by concomitant intravitreal (6x with a total dose of $216 \mu \mathrm{g}$ ) and intracameral $(7 \times$ with a total dose of $15.8 \mu \mathrm{g})$. Intra-arterial and intravitreal chemotherapies were performed as previously described $[9,10]$. The technique of intracameral injection, performed under pharmacologic suppression of aqueous secretion (acetazolamide $5 \mathrm{mg} / \mathrm{kg}$ ), is described in Figure 3 and illustrated by a video (see online suppl. video; for all online suppl. material, see www. 
Fig. 3. Technique of intracameral injection. a, a' Long-needle passage ( $34 \mathrm{G}$ ) across peripheral clear cornea. b Complete aspiration of the aqueous volume contained in the anterior and posterior chambers. This maneuver is facilitated by indenting the eye with a scleral depressor (not illustrated) just posteriorly to the limbus (see online suppl. video). c Syringe exchange with melphalan at a concentration of $15 \mu \mathrm{g} / \mathrm{mL}$. d Melphalan injection of $1 / 3$ (paracentesis volume minus the volume to be injected into the vitreous) into the anterior chamber. e Perforation of the iris root at a tumor-free meridian selected by ultrasonic biomicroscopy to position the needle in the posterior chamber. $f$ Transiridal injection into the posterior chamber of the remaining $2 / 3$ (paracentesis volume minus the volume to be injected into the vitreous) with anterior chamber retrofilling. In total, the mean intracameral injection volume was $0.35 \mathrm{~mL} . \mathbf{g}$ Triple freeze and thaw cryoapplication at the entry site.

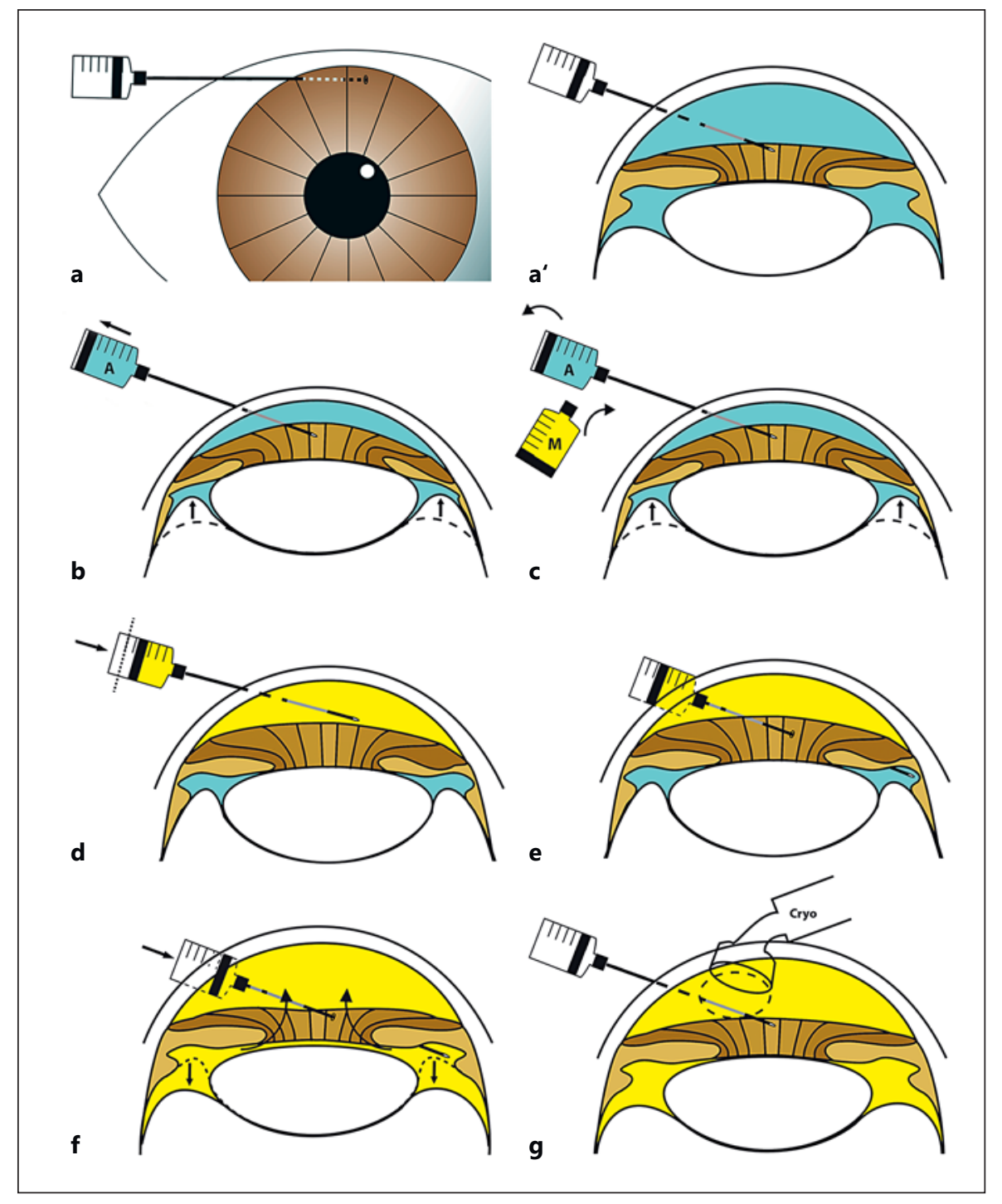

karger.com/doi/10.1159/000453617). The concentration of melphalan injected in the $\mathrm{AC}$ was $6 \mu \mathrm{g} / \mathrm{mL}(3 \times)$ at the beginning and was progressively increased to $8 \mu \mathrm{g} / \mathrm{mL}(2 \times)$ and $10 \mu \mathrm{g} / \mathrm{mL}(2 \times)$ with no effect on endothelial cell density as monitored by confocal microscopy.

Anterior segment involvement being a controversial risk factor for metastasis, the issue of preventive systemic chemotherapy was delayed. However, at the end of this first-line eye-targeted treatment, 4 monthly cycles of systemic preventive chemotherapy (etoposide and carboplatin) were given.

All 3 compartments were under control with time to success for retina, vitreous, and anterior segment of 24, 107, and 89 days, respectively (Fig. 2d-f). The tumor response in the AC was monitored by cytopathological analysis (Fig. $4 \mathrm{a}-\mathrm{c}$ ) and cell culture (Fig. 4d-g). Cytopathology was initially positive for retinoblastoma cells and spheres staining positive for synaptophysin (Fig. 4c) but was found to be negative following the second intracameral injection. As documented by cell culture, both the number of ag- gregates (Fig. 4d) and cells per aggregate (Fig. 4e) dropped to zero following the second intracameral injection, with the number of individual living cells nullified reaching $100 \%$ Trypan blue-positive cells after the third injection (Fig. 4f, g).

An aqueous relapse was noted 3.5 months later on gonioscopy (Fig. 2g) and cell culture (Fig. $4 \mathrm{~d}-\mathrm{g}$ ), arising from the posterior chamber. Considering that the initial 7 intracameral injections were delivered to the AC only, we hypothesized that the recurrence was caused by an underdosage of melphalan in the posterior chamber secondary to drug dilution by ciliary secretion and inverse iridolenticular block occurring during the injection when performed in the AC alone. The injection technique was modified to target the posterior chamber across the peripheral iris with 6 combined $\mathrm{AC}$ and posterior chamber injections $(15 \mu \mathrm{g} / \mathrm{mL}$ with a total dose of $35 \mu \mathrm{g}$ ). Four concomitant intravitreal injections (total dose of $140 \mu \mathrm{g}$ ) were applied to prevent any cross-contamination between the vitreous and aqueous compartments. Complete and stable regression of retinoblastoma was achieved thereafter. 


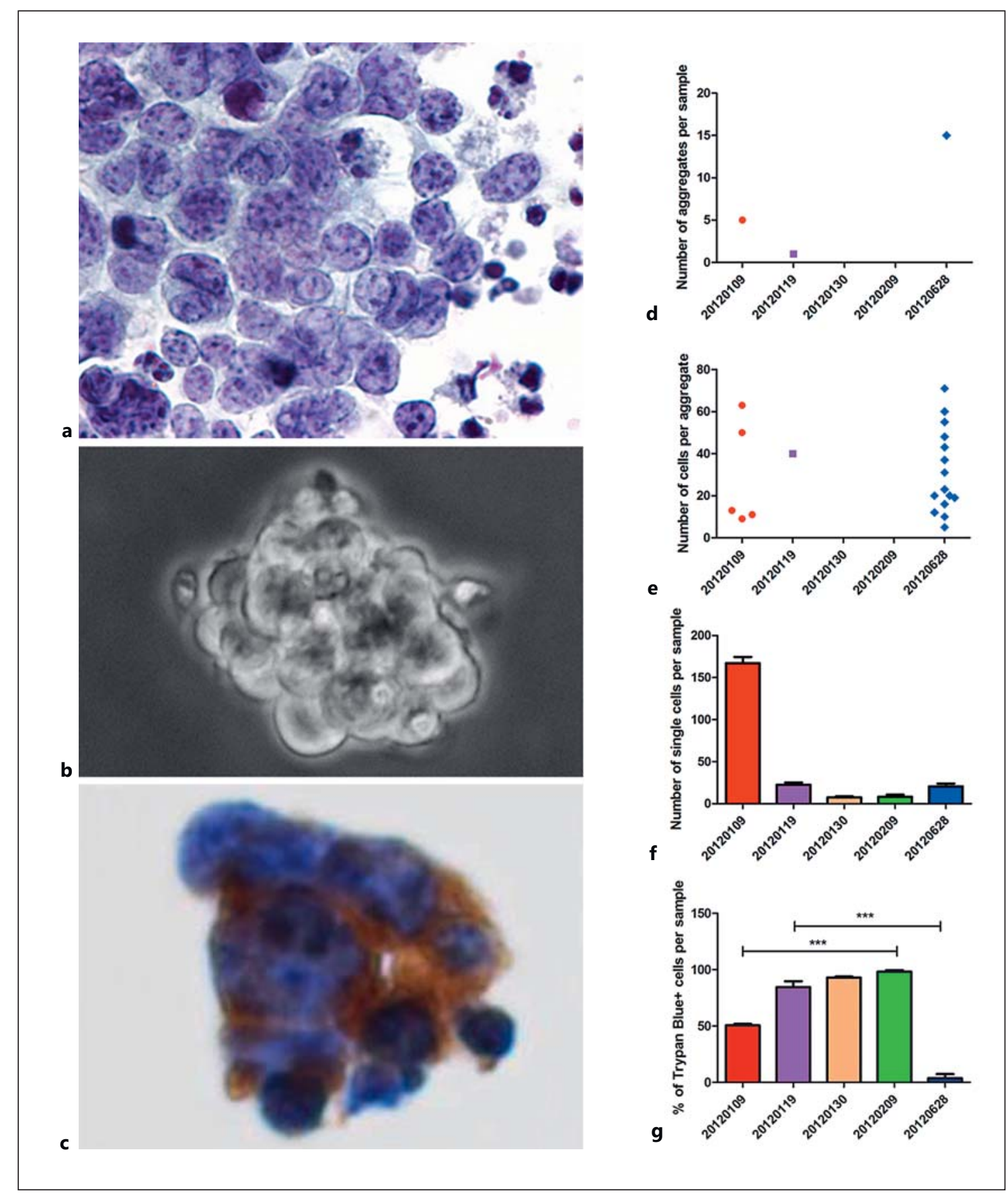

Fig. 4. Monitoring of tumor response in the anterior chamber by cytopathological analysis (a-c) and cell culture $(\mathbf{d}-\mathbf{g})$. a Isolated, small- to medium-sized malignant cells with granular chromatin and scant cytoplasm. Some apoptotic nuclei are present in the background (liquid-based cytology, Papanicolaou staining, $\times 400$ ). b Bright-field micrograph $(\times 400)$ of 1 out of 5 aggregates detected in culture after the first sampling (January 9, 2012). c A group of malignant cells express the immunocytochemical marker syn- aptophysin (clone 27G12, dilution 1:100, Leica Biosystems), consistent with retinoblastoma cells (liquid-based cytology, $\times 400$ ). d-g Quantification of the number of aggregates (d), cells per aggregate (e), individual cells (f), and dying cells (Trypan blue positive) (g) calculated on samples harvested before each intracameral injection. 20120109, 20120119, 20120130, 20120209, 20120628, day of sampling (year/month/day). ${ }^{* * *} \mathrm{p}<0.001$. 

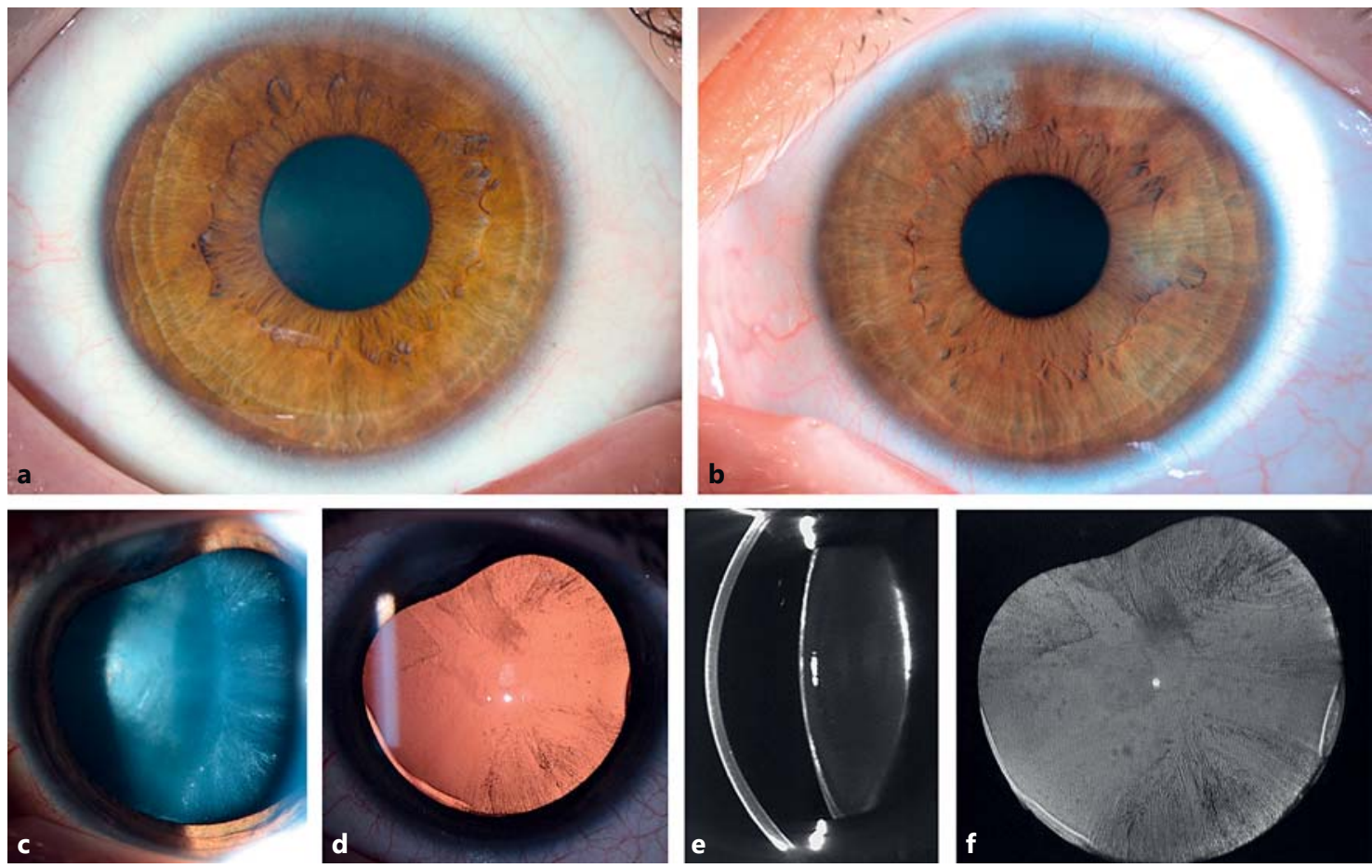

Fig. 5. Iris and lens toxicity. a, b Biomicroscopic views of the iris with hypochromic heterochromia. c, d Biomicroscopic views of cortical opacification of the lens. e, $\mathbf{f}$ Scheimpflug photography of cortical opacification of the lens.

In terms of toxicity, the patient developed hypochromic heterochromia, with no pigment epithelial loss (no iris transillumination) and no stromal thinning on UBM (Fig. 5a, b), and cortical opacification of the lens (Fig. $5 \mathrm{c}-\mathrm{f}$ ) 7 months after the first intracameral injection, requiring cataract surgery with intraocular multifocal lens implantation 15 months later. Corneal endothelial cell density was monitored from presentation and remained unchanged over the injection period with a slight drop of $<2 \%$ after the cataract surgery (pre- and postoperative mean cell count was 2,724 and 2,673 cells $/ \mathrm{mm}^{2}$, respectively, with no morphologic changes).

At 5 years' follow-up, the patient is tumor free with binocular normal vision (20/20 in both eyes). Molecular genetic blood analysis by sequencing did not reveal any RB1 mutation.

\section{Discussion}

Aqueous seeding has remained an intractable form of retinoblastoma due to a sanctuary effect linked to insufficient drug bioavailability in the AC, despite direct ophthalmic artery or intravitreal delivery, to achieve an antitumor effect [11].

Anterior segment invasion as a risk factor for metastasis, although controversial, is not considered to add a sig- nificant risk for extraocular relapse when isolated [12, 13]. Its presence is, however, synonymous with enucleation. Earlier this year, Shields et al. [4] published the first successful attempt to control aqueous seeding in 3 eyes with anterior diffuse retinoblastoma devoid of any retinal or vitreous involvement by means of iodine plaque therapy delivered to the entire anterior segment, including the ciliary body. At a mean follow-up of 35 months, these authors report complete remission in all 3 cases and satisfactory visual outcome despite the occurrence of a radio-induced cataract requiring surgery at a mean followup of 16 months. Corneal limbal stem cell insufficiency and radiation-induced glaucoma are, however, likely to compromise long-term functional results. Given that the tumor thickness ranged from 3 to $9 \mathrm{~mm}$, the peripheral retina, macula, and optic nerve head were also exposed to a potentially sight-threatening dose of radiation. In addition, the lateral dosimetry characterizing high-energy gamma Curie therapy cannot entirely spare the normal surrounding orbit, which would be contraindicated in a germline RB1 carrier.

In the present report, we describe a safe and efficient way to control aqueous seeding provided that (1) the in- 
jection is targeting both anterior and posterior chambers across the iris root at a tumor-free meridian selected by UBM, (2) the concentration of the injected solution of melphalan is higher than the tumoricidal dose found in vitro by Inomata and Kaneko [14], (3) the ciliary secretion is pharmacologically suppressed to prevent dilution of the drug, (4) the source of the seeding is destroyed to prevent relapse, and (5) the vitreous is concomitantly injected to prevent vitreous-to-aqueous cross-contamination. The toxicity encountered was limited to the lens and iris, preserving long-term visual potential.

To the best of our knowledge, this is the first report of a cure for seeding in the aqueous arising from a vitreoretinal tumor source. More recently, we had a second patient who developed secondary aqueous seeding linked to a peripheral ciliary relapse. The same protocol was applied to control the aqueous seeding concomitantly with a plaque centered on the ciliary body, but without systemic preventive chemotherapy [13]. Complete remission was obtained with an event-free follow-up of 3 years [15]. Since then, intracameral chemotherapy has benefited 10 additional cases [Munier F.L. et al., in preparation]. In addition, this protocol was made available across Europe on request and was successfully administered in at least 1 patient with only 1 eye [Desjardin L., pers. commun.].
In summary, we have described a new route of targeted chemotherapy consisting of direct intracameral delivery of melphalan. The associated toxicity is compatible with long-term preservation of the visual function, including normal visual acuity and full binocularity, as shown here.

\section{Acknowledgements}

The authors thank the patient and her family. We also thank Marc Curchod and Yann Leuba for technical assistance.

\section{Statement of Ethics}

Informed consent was obtained, and the study protocol was approved by the institutional review board.

\section{Disclosure Statement}

All authors have no conflicts of interest related to the present research.

\section{References}

1 Munier FL: Classification and management of seeds in retinoblastoma. Ellsworth Lecture Ghent August 24th 2013. Ophthalmic Genet 2014;35:193-207.

2 Abramson DH, Dunkel IJ, Brodie SE, Kim JW, Gobin YP: A phase I/II study of direct intraarterial (ophthalmic artery) chemotherapy with melphalan for intraocular retinoblastoma: initial results. Ophthalmology 2008;115:1398-1404.

3 Munier FL, Gaillard MC, Balmer A, Soliman S, Podilsky G, Moulin AP, Beck-Popovic M: Intravitreal chemotherapy for vitreous disease in retinoblastoma revisited: from prohibition to conditional indications. Br J Ophthalmol 2012;96:1078-1083.

4 Shields CL, Lally SE, Manjandavida FP, Leahey AM, Shields JA: Diffuse anterior retinoblastoma with globe salvage and visual preservation in 3 consecutive cases. Ophthalmology 2016;123:378-384.

5 Haik BG, Dunleavy SA, Cooke C, Ellsworth RM, Abramson DH, Smith ME, Karcioglu ZA: Retinoblastoma with anterior chamber extension. Ophthalmology 1987;94:367-370.

Intracameral Chemotherapy for Aqueous Seeding in Retinoblastoma
6 Kaliki S, Shields CL, Rojanaporn D, Al-Dahmash S, McLaughlin JP, Shields JA, Eagle RC Jr: High-risk retinoblastoma based on international classification of retinoblastoma: analysis of 519 enucleated eyes. Ophthalmology 2013;120:997-1003.

7 Shields CL, Ghassemi F, Tuncer S, Thangappan A, Shields JA: Clinical spectrum of diffuse infiltrating retinoblastoma in 34 consecutive eyes. Ophthalmology 2008;115:2253-2258.

8 Jijelava KP, Grossniklaus HE: Diffuse anterior retinoblastoma: a review. Saudi J Ophthalmol 2013;27:135-139.

9 Munier FL, Balmer A, Gaillard MC, BeckPopovic M, Bovey E, Binaghi S: Occurrence of sectoral choroidal occlusive vasculopathy and retinal arteriolar embolization following superselective ophthalmic artery chemotherapy for advanced intraocular retinoblastoma. Retina 2011;31:566-573.

10 Munier FL, Soliman S, Moulin A, Gaillard MC, Balmer A, Beck-Popovic M: Profiling safety of intravitreal injections for retinoblastoma using an anti-reflux procedure and sterilization of the needle track. Br J Ophthalmol 2012;96:1084-1087.
11 Buitrago E, Winter U, Williams G, Asprea M, Chantada G, Schaiquevich P: Pharmacokinetics of melphalan after intravitreal injection in a rabbit model. J Ocul Pharmacol Ther 2016; 32:230-235.

12 Uusitalo MS, Van Quill KR, Scott IU, Matthay KK, Murray TG, O'Brien JM: Evaluation of chemoprophylaxis in patients with unilateral retinoblastoma with high-risk features on histopathologic examination. Arch Ophthalmol 2001;119:41-48.

13 Baroni LV, Sampor C, Fandiño A, Solernou V, Demirdjian G, de Davila MT, Chantada GL: Anterior segment invasion in retinoblastoma: is it a risk factor for extraocular relapse? J Pediatr Hematol Oncol 2014;36:e509-e512.

14 Inomata M, Kaneko A: Chemosensitivity profiles of primary and cultured retinoblastoma cells in a human tumor clonogenic assay. Jpn J Cancer Res 1987;78:858-868.

15 Munier FL, Gaillard MC, Decembrini S, et al: Aqueous seeding: fall of the ultimate intraocular retinoblastoma sanctuary by a new in situ chemotherapy technique. Invest Ophthalmol Vis Sci 2015;56:1663. 